\title{
Isolation Precautions for Visitors
}

\author{
L. Silvia Munoz-Price, MD, PhD; ${ }^{1}$ David B. Banach, MD, MPH, MS; ${ }^{2}$ Gonzalo Bearman, MD, MPH; ${ }^{3}$ \\ Jane M. Gould, MD; ${ }^{4}$ Surbhi Leekha, MBBS; ${ }^{5}$ Daniel J. Morgan, MD, MS $;{ }^{6}$ Tara N. Palmore, MD $;^{7}$ \\ Mark E. Rupp, MD; ${ }^{8}$ David J. Weber, MD, MPH; ${ }^{9}$ Timothy L. Wiemken, $\mathrm{PhD}^{10}$
}

Transmission of organisms within the hospital setting has become a topic of major concern not only for patients and healthcare facilities but also for government agencies and the general public. This increased awareness has occurred in part due to the spread of organisms that have limited treatment options, such as carbapenem-resistant Enterobacteriaceae (CRE), as well as the heightened recognition that many hospital-associated infections (HAIs) are preventable. A large body of literature shows that horizontal transmission of multidrug-resistant organisms involves the hands, and potentially the attire, of healthcare workers (HCWs). This evidence provides the rationale for the use of standard and contact isolation precautions among HCWs. However, the health risks to visitors and the role of visitors in the horizontal transmission of pathogens within acute care hospitals is not as clearly defined. Consequently, uncertainty remains regarding which precautions visitors should take when interacting with patients placed on isolation precautions. Frequent arguments against the use of isolation precautions among visitors include lack of visitor movement between patient rooms, the difficulty of educating visitors, and the difficulty of enforcing compliance with isolation practices.

This manuscript was created to provide general recommendations for isolation precautions among visitors based on the literature and a survey of the Society for Healthcare Epidemiology of America (SHEA) membership and SHEA Research Network (SRN). For endemic situations with methicillin-resistant Staphylococcus aureus (MRSA) and vancomycin-resistant enterococci (VRE), we recommend not using contact isolation precautions, although visitors interacting with multiple patients should use isolation practices similar to those of HCWs. Utilization of contact precautions should be considered for visitors to patients with extensively drug-resistant Gram-negative organisms (eg, Klebsiella pneumoniae carbapenemase (KPC) or enteric pathogens with diarrhea, such as Clostridium difficile and norovirus). Visitors with extensive documented exposure to the symptomatic patient prior to hospitalization such as parents/guardians/ family members may be excluded from isolation precautions. These recommendations should be adapted to patient populations and individual hospital needs.

\section{INTENDED USE}

This document is intended to help healthcare facilities develop or modify policies related to the use of isolation precautions by visitors. The contents of the literature review and the survey contain information pertaining predominantly to adult and pediatric acute care hospitals. However, personnel in other care settings may find the recommendations useful as they consider this issue.

\section{SHEA WRITING GROUP}

The writing group consists of volunteers among SHEA members, most being current or past members of the SHEA Guidelines Committee. Additionally, all authors are involved at their respective organizations in the development of policies pertaining to isolation precautions.

\section{KEY AREAS ADDRESSED}

Using a combination of a literature review and a survey, we aimed to do the following:

1. Summarize the evidence for the role of visitors on the horizontal transmission of pathogenic organisms within the hospital setting, including outbreak situations.

2. Evaluate the scientific literature supporting the use of contact or respiratory (droplet or airborne) isolation precautions, including hand hygiene, among visitors.

Affiliations: 1. Medical College of Wisconsin, Milwaukee, Wisconsin; 2. Yale School of Medicine, New Haven, Connecticut; 3. Virginia Commonwealth University, Richmond, Virginia; 4. St. Christopher's Hospital for Children, Drexel University College of Medicine, Philadelphia Department of Public Health, Philadelphia, Pennsylvania; 5. University of Maryland Baltimore, Department of Epidemiology and Public Health, Baltimore, Maryland; 6. University of Maryland, Baltimore, Maryland; 7. National Institutes of Health, Bethesda, Maryland; 8. University of Nebraska Medical Center, Omaha, Nebraska; 9. University of North Carolina, Chapel Hill, North Carolina; 10. University of Louisville, Louisville, Kentucky.

Received February 24, 2015; accepted February 25, 2015; electronically published April 10, 2015

(c) 2015 by The Society for Healthcare Epidemiology of America. All rights reserved. 0899-823X/2015/3607-0001. DOI: 10.1017/ice.2015.67 
3. Characterize the current infection prevention practices used for visitors as per a survey conducted among SHEA members.

\section{GUIDANCE AND RECOMMENDATION FORMAT}

This topic lacks the level of evidence required for a more formal guideline using a Grading of Recommendations Assessment, Development and Evaluation (GRADE) system. ${ }^{1}$ Therefore, no grading of the evidence level is provided for individual recommendations. The guidance statement is based on synthesis of limited evidence, theoretical rationale, practical considerations, a survey of SHEA membership and the SHEA Research Network, author opinion, and the consideration of potential harm, where applicable.

\section{GUIDANCE STATEMENT}

The following expert recommendations attempt to balance visitor and patient safety, the potential for the spread of pathogens within the hospital, the psychosocial implications of isolation practices, and the feasibility of enforcement of isolation precautions among visitors. The recommendations that follow are intended for endemic pathogens in nonoutbreak situations for which contact isolation measures are often used for healthcare providers (ie, MRSA and VRE). In outbreaks or situations of increased transmission, practices involving hospital visitation should be considered on a situational basis. Although these recommendations are primarily intended for acute care facilities, similar considerations may apply to other healthcare settings (eg, post-acute care).

As the SHEA working group for isolation precautions for visitors in acute care hospitals, we recommend the following:

I. Given the limited scientific evidence on the subject, studies designed to evaluate the role of visitors in the horizontal transmission of pathogens should be performed.

II. Until the appropriate studies are performed, the use of isolation precautions among visitors should be guided by the specific pathogen, the underlying infectious condition, and the endemicity of the organism in both the hospital and the surrounding community.

A. All visitors should perform hand hygiene prior to entering a patient room and immediately after leaving the room. Both hand washing with soap and water and proper use of an alcohol-based hand rub are acceptable means of hand hygiene. Institutions should ensure that sinks and alcoholbased hand rub stations are easily accessible to visitors. Visitors should be educated on the importance of frequent hand hygiene in the hospital setting and on the available options and proper techniques for performing hand hygiene. ${ }^{2}$

Rationale: Hand hygiene is a well-established means of reducing the microbial burden on hands and preventing pathogen transmission. In the healthcare setting hand hygiene can prevent the spread of microorganisms between patients and visitors. Promoting hand hygiene through use of visual cues and reminders and ensuring that sinks and alcohol-based hand rub stations are readily accessible can lead to increased rates of adherence among hospital visitors.

B. For endemic situations with MRSA and VRE we recommend not using contact isolation precautions for visitors in routine circumstances.

Rationale: In many areas, MRSA and VRE are prevalent in the community and limiting the contact of visitors is probably not an effective intervention. However, we suggest special consideration (eg, limiting or precluding visitation, use of gowns/gloves) for certain types of visitors, such as severely immunosuppressed individuals or those who are unable to practice good hand hygiene.

C. If visitors to patients with MRSA or VRE will be interacting with multiple patients, they may be at greater risk for transmitting pathogens between patients and should use isolation practices in a fashion similar to that of healthcare workers (HCWs). This might be the case for visitors of patients with long inpatient stays, such as after transplantation, in which multiple families and patients might have more frequent and closer interactions with each other.

D. Utilization of contact precautions should be considered for visitors to patients either colonized or infected with extensively drug-resistant Gram-negative organisms (eg, KPC).

Rationale: In most regions of the United States, these highly resistant pathogens are not widely prevalent in the community and compliance with contact precautions might protect visitors during these exposures. Additionally, this intervention might limit the spread of organisms in the hospital.

E. For visitors of patients infected with enteric pathogens (eg, $C$. difficile, norovirus), we suggest the use of contact isolation precautions. ${ }^{3}$

Rationale: The prevalence of some of these pathogens in the community is either unknown or thought to be low; acquisition of these pathogens can be potentially harmful to visitors.

F. For parents/guardians/visitors with extended stay in a patient's room, including overnight visitation, isolation precautions may not be practical. The risk of infection for parents/guardians/visitors is likely reduced if they practice good hand hygiene, and any additional benefit of wearing gowns and gloves in these scenarios of prolonged exposure is unclear.

In special situations, in which patients acquire new transmissible infections after admission to the hospital, protection of parent/guardian/visitor by the use of isolation precautions may be considered. Examples of such scenarios could include parents of children with hospital onset of C. difficile infection or colonization/infection with extensively antibiotic-resistant Gram-negative bacilli (eg, KPC). If parents or other visitors are assisting HCWs with providing care, standard precautions should be utilized, including the use of gowns and gloves, if contact with blood, body fluids, or nonintact skin is anticipated.

Rationale: The added benefit of contact isolation must be weighed against logistical barriers to the prolonged use of 
isolation gear. Individualized considerations should be undertaken for visitors that may be spending extended time with their hospitalized child, including sleeping and eating in the room.

G. For visitors to rooms of patients on droplet precautions, we suggest the use of surgical masks. However, visitors with extensive documented exposure to the symptomatic patient prior to hospitalization such as parents/guardians/ family members may be excluded from these precautions; they may either be immune to the infectious agent or already in the incubation period. Among pediatric patients, further considerations should include interference with bonding. Isolation requirements should be considered on a case-by-case basis in some circumstances (eg, highly virulent pathogen). Additionally, healthcare facilities should generally restrict visitation by any ill individual or family member (eg, active cough, fever).

H. For visitors to patients on airborne precautions, we recommend the use of surgical masks. An alternative is an N95 respirator; however, this equipment is best used with training and fit testing. Visitors with extensive documented exposure to the symptomatic patient prior to hospitalization, such as household contacts, may be excluded from these precautions as they may be either immune to the infectious agent or already in the incubation period. In those instances in which prior extensive exposure is not documented and N-95 or higher respiratory protection is recommended for the patient, consideration should be given to limiting visitation for those who have not been fit tested. In these instances, education of visitors is important and facilities should clearly document these communications. As previously noted in the recommendations for droplet precautions, further considerations should include interference with bonding. As stated previously, hospitals should consider restricting entry of visitors that are symptomatic (eg, active cough, fever).

Rationale: Pathogens that spread by either droplet or airborne pathways should generally be considered potentially harmful to visitors. As discussed in the ensuing text, this is one of the few scenarios in which visitors have been proven to spread organisms within the hospital setting. With regard to airborne isolation, the use of N95 respirators among unfitted visitors is not warranted. If a visitor is considered at risk of an airborne pathogen and lacks previous exposure, then consideration should be given to limiting entrance. Again, visitor education and medico-legal considerations should be considered and documented in the record.

I. In situations in which heightened horizontal transmission is detected (eg, outbreak or increased baseline rates) or a novel, potentially virulent pathogen is suspected or identified (eg, Ebola virus, Middle East respiratory syndrome coronavirus [MERS-coV], severe acute respiratory syndrome [SARS], etc.), enforcing isolation precautions among visitors (including parents/guardians/siblings) should be prioritized. Hospitals should consider restricting nonessential visitors, limiting the number of visitors at one time, as well as developing policies and infrastructure to monitor and enforce adherence to appropriate isolation precautions among visitors in these circumstances.

Rationale: Horizontal transmission of pathogens within the hospital usually occurs via vectors (eg, HCWs) or vehicles (eg, contaminated surfaces, contaminated air). In situations in which there is an increase in clonal transmission of organisms or a novel and virulent organism has been identified, enforcement of isolation precautions among visitors is frequently used as one of the interventions within an infection control bundle. Additionally, alternative methods of communication between visitors and patients (eg, video conferencing) should be explored.

III. These recommendations should be adapted to individual hospital needs and patient populations. Additionally, hospitals should only consider writing policies regarding visitors when they can be realistically enforced and regularly evaluated for compliance. Resources should be allocated to hospital infection prevention programs to develop infrastructure to scale up visitor-related infection control policy enforcement in settings of heightened horizontal transmission.

\section{METHODS}

Between the months of February and June 2014 we searched the PubMed/MEDLINE database for articles pertaining to visitors and infection prevention in healthcare settings. The literature review was limited to articles and reports published in English, and following an initial search, we focused on studies involving visitors and contact precautions, respiratory precautions, and hand hygiene. We also searched for articles reporting situations in which visitors may have been involved in HAIs or transmission. An independent search was performed to identify published studies focusing on visitors and infection control among pediatric patient populations.

Additionally, during the months of April to June 2014, a survey was sent to SHEA membership and SHEA Research Network members to investigate infection control practices related to visitors at their respective institutions.

\section{RESULT S}

\section{Literature Review (Table 1)}

No published studies have evaluated the impact of visitor adherence with contact precautions in reducing the spread of multidrug-resistant organisms. Although visitors spend more time in patient rooms than do $\mathrm{HCWs}^{4}{ }^{4}$ the extent of contact between visitors and patients likely varies. A survey of hospital visitors suggests that most visitors understand the purpose of 
TABLE 1. Summary of literature review on Isolation Precautions for Visitors

\begin{tabular}{|c|c|c|}
\hline Year & Lead Author & Methodology \\
\hline 2002 & Afif et $\mathrm{al}^{6}$ & $\begin{array}{l}\text { Observational study ( } \mathrm{n}=65 \text { visitors) on a } \\
\text { medical unit. Only visitors to patients with } \\
\text { MRSA colonization or infection were } \\
\text { included }\end{array}$ \\
\hline 2004 & Beck et $\mathrm{al}^{20}$ & Review of procedures for SARS \\
\hline 2012 & Birnbach et $\mathrm{al}^{11}$ & $\begin{array}{l}\text { Observational study comparing } 3 \\
\text { interventions: a sign mandating all visitors to } \\
\text { use hand gel, a free-standing hand gel } \\
\text { dispenser directly in front of a security desk, } \\
\text { and a combination of a freestanding hand gel } \\
\text { dispenser and a sign }\end{array}$ \\
\hline
\end{tabular}

$1995 \quad$ Christie et $\mathrm{al}^{19}$

Overview of measures to stop a pertussis outbreak in 1 facility observations) at 3 sites within a single hospital network entries) in ICUs in 3 hospitals; duration and level of contact recorded motion sensor-triggered audible hand hygiene reminder installed at hospital ward entrances

$2011 \quad$ Gupta et al ${ }^{18}$

Survey of newborn hospitals for influenza virus isolation during and after 2009 pandemic ( $\mathrm{n}=111$ during and $\mathrm{n}=48$ after)

Kellerman et $\mathrm{al}^{17}$ Direct observation of rooms containing patients with tuberculosis ( $\mathrm{n}=30$ patients)

Kellerman et al ${ }^{16}$ Survey of freestanding children's hospitals $(\mathrm{n}=195)$

$2007 \quad$ Manian et $\mathrm{al}^{8}$

Observational cohort study ( $\mathrm{n}=2,110$ persons: 1,504 HCWs and 606 non-HCWs visitors) at a tertiary care teaching hospital

Nishimura $^{12}$

Observational study using a ceiling-mounted video camera connected to a time-lapse video cassette recorder

\section{Findings}

Compliance with MRSA precautions defined as compliance with glove, gown, and hand hygiene measures. Compliance with MRSA precautions among visitors was $11 \%$, the second lowest among 6 groups studied.

Outlined tips for facilitating compliance with respiratory isolation

Hand hygiene compliance was $52 \%$ at baseline and did not improve significantly when the desk sign was provided as a cue. Compliance improved with use of the freestanding hand gel dispenser and the sign and dispenser combination. The degree of improvement with the sign and dispenser combination over the dispenser was not statistically significant.

Procedures for visitors included wearing surgical masks, restricted access for $<14$ years of age, preventing visitation to neonatal unit except for parents, grandparents or guardians, and creating a temporary child care service

Prior to entering rooms of patients on contact precautions adherence among visitors was hand hygiene (10.8\%), gloves (46.9\%), gown (63\%). After room exit adherence among visitors were hand hygiene $(9.7 \%)$, gloves $(52.4 \%)$, and gown $(57.9 \%)$.

Visitors spent more time in patient rooms than any other group (mean 14 minutes per visit). Contact with either patients or patient blood/body fluid occurred in $51.9 \%$ of visitor encounters, and $28.5 \%$ had contact with the environment. Only $33 \%$ of personal visitors wore gloves when touching patients.

Glove use among visitors with contact with blood/body fluids were 14/21 (66\%) for patients on contact precautions and 2/28 (7\%) for patients not on contact precautions.

Overall hand hygiene adherence increased from $7.6 \%$ to $49.9 \%(P<.001)$. The adherence of visitors and nonclinical staff increased immediately from $10.6 \%$ to $63.7 \%$ and from $5.3 \%$ to $34.8 \%$, respectively $(P<.001)$.

Policies became less significantly stringent after the pandemic. More facilities allowed direct breastfeeding and direct contact with mother/infant and did not restrict access to facility.

In 134 visits, visitors left negative pressure room doors open longer than HCWs, wore masks appropriately $55 \%$ of the time, and wore approved masks only $59 \%$ of the time.

Tuberculosis-specific policies varied and were not present in all facilities. Most facilities restricted visitor access to rooms.

Compliance with gown use among visitors was low (65\%) though higher among visitors to patients in ICUs than in general wards (OR, 10; 95\% CI, 6.0-17.0). In the ICU, gown use was highly predictive of glove use.

Hand hygiene compliance among visitors (94\%) was significantly higher than among HCWs $(71 \%)(P<.001)$. Hand washing compliance among HCWs before entering the ICU was low.

Compliance among all groups with strict isolation (65\%) was better than with wound/skin $(40 \%)$ or excretion/secretion $(36 \%)$ isolation $(P<.01)$. Visitors were more compliant than HCWs $(88 \%$ versus $41 \%$; $P<.01)$. 
TABLE 1. Continued

\begin{tabular}{|c|c|c|c|}
\hline Year & Lead Author & Methodology & Findings \\
\hline 2010 & Randle $^{14}$ & $\begin{array}{l}\text { Observational study measured HCWs, patient } \\
\text { and visitor hand hygiene compliance in } 2 \\
\text { hospital wards using the ' } 5 \text { moments of hand } \\
\text { hygiene' observation tool }\end{array}$ & $\begin{array}{l}\text { Among HCWs, compliance was } 47 \% \text { for doctors, } 75 \% \text { for } \\
\text { nurses, } 78 \% \text { for allied health professionals, and } 59 \% \text { for } \\
\text { ancillary and other staff }(P<.001) \text {. There was no } \\
\text { difference in compliance between patients and visitors } \\
(56 \% \text { vs } 57 \%, P=.87) \text {. }\end{array}$ \\
\hline 2014 & Roidad et $\mathrm{al}^{5}$ & $\begin{array}{l}\text { Survey of visitors of patients in contact } \\
\text { isolation }\end{array}$ & $\begin{array}{l}\text { Visitors understood the purpose of contact isolation and felt } \\
\text { that contact isolation improves care. Half of visitors } \\
\text { surveyed felt that visitors should be required to wear } \\
\text { gowns and gloves when visiting patients in contact } \\
\text { isolation. }\end{array}$ \\
\hline 2010 & Tan et $\mathrm{al}^{15}$ & $\begin{array}{l}\text { Survey of attitudes toward influenza response } \\
\text { measures ( } \mathrm{n}=10 \text { visitors })\end{array}$ & Visitors found measures to be inconvenient. \\
\hline 2007 & Weber et $\mathrm{al}^{9}$ & $\begin{array}{l}\text { Observational survey ( } \mathrm{n}=69 \text { visitors) on } \\
\text { medical, pediatric and intensive care units }\end{array}$ & $\begin{array}{l}\text { Visitor rates of compliance with the specific requirements of } \\
\text { contact isolation (ie, percentage of instances in which } \\
\text { visitors wore appropriate personal protective equipment) } \\
\text { were } 49.3 \% \text { for gowns and } 37.1 \% \text { for gloves. }\end{array}$ \\
\hline
\end{tabular}

NOTE. ICU, intensive care unit; MRSA, methicillin-resistant Staphylococcus aureus; SARS, severe acute respiratory syndrome; HCWs, healthcare workers; OR, odds ratio; $\mathrm{CI}$, confidence inteet alrval.

contact precautions, believe that contact precautions improved patient care and feel that contact precautions would not impact the duration of time visitors spend with patients. ${ }^{5}$ In this survey, approximately $50 \%$ of those surveyed supported glove and gown use among visitors of patients on contact precautions.

We identified 5 studies in which adherence with contact isolation practices among hospital visitors was evaluated. ${ }^{6-10}$ Marked heterogeneity was observed among study populations and settings though all included small numbers of visitors. All studies were observational cohort studies using trained observers to monitor adherence. Most studies included both visitors and HCWs. ${ }^{6-10} \mathrm{~A}$ total of 4 studies assessed adherence to different components of contact precautions including hand hygiene and gown and glove use; 2 studies $^{6,10}$ reported adherence to contact precautions as a composite measure of all components. Only 1 study focused specifically on $\mathrm{MRSA}^{6}$ and revealed low rates of compliance with contact precautions among visitors $(11 \%)$. No studies focused on other multidrugresistant bacteria or on C. difficile. Visitor adherence components of contact precautions, specifically the use of gowns and gloves, varied among the studies. Adherence to gown use procedures ranged from $49 \%$ to $65 \% .^{7-9}$ Another study demonstrated that compliance with glove use and hand hygiene procedures among visitors to patients on contact precautions was lower than compliance with gown use. ${ }^{6}$ Compared with HCWs, adherence among visitors was generally lower, although 1 study of visitors to a surgical intensive care unit (ICU) revealed that rates of adherence to all isolation precautions (ie, secretion/excretion precautions, wound precautions, and strict isolation) were higher among visitors than HCWs $(88 \%$ vs $41 \%) .{ }^{10}$ Comparing different healthcare settings, 1 study demonstrated that compliance with gown and glove use among visitors was higher in the ICU setting than in the adult and pediatric medical units. ${ }^{7}$

\section{Visitors and Hand Hygiene}

Visitor compliance with hand hygiene procedures has been assessed in a few studies in different hospital locations. In common areas of hospitals, visitor compliance with hand hygiene procedures has been monitored in relation to interventions designed to make hand hygiene easier and to remind visitors to perform hand hygiene. Placement of an alcohol hand-rub dispenser and a sign reminding visitors to perform hand hygiene in a hospital lobby increased the visitor hand hygiene rate from $<1 \%$ to $12 \% .{ }^{11}$ Reminders to perform hand hygiene placed at the entrance of an ICU increased visitor compliance. In a Japanese ICU that also required visitors to change shoes and don gowns, a sign and multiple hand hygiene stations led to $94 \%$ compliance with hand hygiene among visitors. ${ }^{12}$ In a more traditional ICU in England, the use of a motion-sensed audio reminder increased the visitor hand hygiene rate from $11 \%$ to $64 \% .{ }^{13}$ A study in 2 English hospitals compared visitor and HCW compliance with hand hygiene related to patient care during standardized World Health Organization (WHO) 5 Moments over 48 hours; visitor hand hygiene compliance was no different than HCW compliance $(57 \%$ vs $56 \%) .{ }^{14}$ In a small sample of visitors to a US hospital, visitor compliance with hand hygiene was approximately $10 \%$ on room entry and exit. ${ }^{7}$ Notably, hand hygiene compliance was much lower than visitor compliance with gown and glove use for patients on contact precautions; compliance with gowns and gloves was approximately $40-60 \%{ }^{7}$ A similar frequency of visitor compliance with hand hygiene was the primary reason for lack of compliance with contact precaution 
in a Canadian hospital in which $10 \%$ overall visitor compliance with contact precautions was observed. ${ }^{6}$ Notably, these studies included minimal description of visitor instruction on hand hygiene; therefore, the wide range of compliance might be associated with variations in the education of visitors.

\section{Visitors and Respiratory Isolation Precautions}

Limited data are available in the literature regarding isolation precautions for visitors of patients on respiratory isolation. No data exist regarding the impact of visitor compliance with respiratory isolation and subsequent infection linked to the visit. A literature review identified 6 articles surveying various aspects of visitors and respiratory precautions. ${ }^{15-20}$ All studies were small and observational or cross-sectional by design. Of these 6 studies, 3 consisted of surveys, ${ }^{15,16,18} 1$ study included direct observation, ${ }^{17}$ and 2 studies described procedures during outbreak settings. ${ }^{19,20}$ Of the 6 studies, 5 focused on pediatric care. ${ }^{16-20}$ Most studies evaluated both visitor and HCW compliance and perceptions with respect to isolation procedures, each with relatively small sample sizes.

Tan et $\mathrm{al}^{15}$ surveyed 10 visitors during an influenza A H1N1 outbreak, with half of respondents indicating that the response measures were an inconvenience. Gupta and Pursley ${ }^{18}$ surveyed infection prevention practices in US neonatal hospital units during and after the $2009 \mathrm{H} 1 \mathrm{~N} 1$ influenza A pandemic. They documented significant differences in the policies and procedures used to prevent virus transmission after the pandemic. For example, after the pandemic, significantly fewer facilities limited direct breastfeeding, separated mother and newborn, and restricted children from various areas of the facility. Christie et $\mathrm{al}^{19}$ described a response during a pertussis outbreak and outlined a number of visitor procedures enforced by staff. These visitor-related interventions included (1) mandatory surgical masks for all visitors upon arrival to the facility where testing was performed, (2) visitor restrictions for children under 14 years of age, (3) restriction of neonatal ICU visitation to parents, grandparents, and legal guardians, and (4) complimentary temporary child care. ${ }^{19}$ Similarly, Beck et $\mathrm{al}^{20}$ summarized interventions used to limit the spread of SARS during the Toronto outbreak. One unique procedure used was to offer incentives and rewards to children to wear masks. In collaboration with the Association for Professionals in Infection Control and the Centers for Disease Control and Prevention, these investigators surveyed multiple facilities caring for pediatric patients with tuberculosis. Of the 195 responses, fewer than half indicated that they had a pediatricspecific tuberculosis control policy. Respondents varied with respect to documentation regarding when to discontinue respiratory isolation. Approximately $70 \%$ of respondents indicate that they restricted visitors to tuberculosis isolation rooms, while $>40 \%$ of respondents denied visitation privileges until tuberculosis status was determined. ${ }^{16}$

Only 1 study directly measured visitor compliance with respiratory isolation. ${ }^{16,17}$ This survey used direct observation to study infection control procedures for pediatric patients with tuberculosis. The investigators evaluated 134 visitors (family members or friends). Visitors tended to leave the negative pressure room door open longer than 30 seconds more often than HCWs. Additionally, visitors only wore the approved respirator in $41 \%$ of occasions, and in only $55 \%$ of these instances were respirators worn correctly. ${ }^{17}$

\section{Visitors and Transmission/Outbreaks}

Visitors have been implicated in some nosocomial outbreaks, and screening visitors and restriction of symptomatic visitors may play an important a role in outbreak control. Some notable examples include outbreaks of tuberculosis, norovirus, and SARS.

Pediatric patients who have active tuberculosis typically acquired the infection from a parent or other adult caregiver, ${ }^{21}$ prompting recommendations that caregivers of pediatric tuberculosis patients be screened for active disease themselves. ${ }^{22}$ George et $\mathrm{al}^{23}$ described a large outbreak at a children's hospital traced to cavitary tuberculosis in a patient's mother. The investigation revealed that 24 pediatric patients who had contact with the mother developed active TB, with an especially high attack rate among immunosuppressed patients. Weinstein et $\mathrm{al}^{24}$ described transmission from a visitor of a pediatric patient to 2 hospital contacts who acquired latent infection.

Because of the highly contagious nature of norovirus and its tendency to cause epidemics in both community and healthcare settings, it is not straightforward to prove a role of visitors in perpetuating nosocomial outbreaks; however, visitor restriction is often part of the outbreak control strategy. ${ }^{25}$ Johnston et al described a large norovirus outbreak affecting $>500$ hospital patients and staff. Initially, visitors were screened for symptoms and symptomatic visitors were restricted for 72 hours. When transmission continued despite these measures, a restriction on all visitation was imposed, with exceptions on a case-by-case basis. ${ }^{26} \mathrm{~A}$ prospective, survey-based study of norovirus outbreaks in 49 Dutch nursing homes showed that restricting symptomatic visitors was the only outbreak control measure that, in multivariate analysis, significantly reduced the residents' odds of acquiring norovirus. ${ }^{27}$

As with norovirus, several papers speculate about the contribution of visitors to nosocomial outbreaks of influenza and other respiratory viruses, but few data are available to support this hypothesis. ${ }^{28-35}$ Nevertheless, restriction of symptomatic visitors or visitors who have had contact with contagious patients has been a core strategy in outbreak control. ${ }^{24,34,36-40}$

The pivotal role of hospital visitors in spreading infection was well documented in the epidemic of SARS in 2003-2004, which was caused by a novel coronavirus that spread in Asia and Canada. Overall, 8,096 cases of SARS and 774 deaths were reported. ${ }^{21}$ As documented in several reports, hospital visitors were part of the transmission cycle within hospitals and in the community: visitors acquired the infection in healthcare 
facilities ${ }^{41}$ and subsequently became a source of transmission to patients and HCWs themselves, ${ }^{42}$ their families, and the community outside the hospital. ${ }^{43}$

A retrospective study identified at least 21 cases in Singapore alone that resulted from transmission by hospital visitors to family and community contacts. ${ }^{43}$ Once the role of visitors in the epidemiology of SARS was appreciated, restrictions were placed on hospital visitation, and recent visitors to wards housing active SARS cases were quarantined. Retrospective assessment of containment strategies at hospitals involved in the epidemic identified incomplete restriction and tracking of visitors (using a visitor log) as weaknesses of the containment strategy that resulted in additional cases. Visitors initially were allowed in the SARS wards with full personal protective equipment, and later, when transmission continued, visitors were disallowed. Similar restrictions on hospital visitors were implemented as SARS control measures in other hospitals. ${ }^{44}$

During the quarantine of hospitals in Toronto and elsewhere, visitors and staff were screened before entry into the facility using questionnaires and thermometers, and visitors whose results were suspicious for SARS were referred to the emergency department. ${ }^{44}$ In some countries, infrared thermal imaging was used to screen large numbers of patients and visitors for elevated body temperature as an initial screen for respiratory viral infection.

\section{Summary of Survey Results}

Between April and May 2014, we sent a survey to all SHEA members and members of the SHEA Research Network to assess their institutional policies (if any) and practices regarding isolation precautions for visitors.

Of 1,520 SHEA members, 314 SHEA members and members of the SHEA Research Network responded to the survey, for a $21 \%$ response rate (Table 2). The majority of respondents were from North America (United States and Canada) (89\%). Most worked at hospitals (91\%); an additional $4 \%$ worked at freestanding children's hospitals; $1 \%$ worked at long-term care facilities; and $0.3 \%$ worked at freestanding clinics. Of 168 respondents, $23 \%$ represented a pediatric facility. The majority of responses were from either university/teaching hospitals $(40 \%)$ or university/teaching-affiliated hospitals (28\%). We received additional responses from nonteaching hospitals (25\%), Veterans Affairs hospitals (3\%), and specialty hospitals (1\%). For hospitals, the mean number of licensed beds was 496. Most respondents were either infection preventionists (50\%) or hospital epidemiologists (39\%).

Most respondents reported that their hospitals posted isolation precautions signs on the doors of isolation rooms (99\%) (Table 3). Specific isolation signs were used by $98 \%$ of respondents for airborne precautions (eg, tuberculosis), contact precautions (eg, MRSA), and droplet precautions (eg, pertussis). Well over half of the respondents had special signs for immunocompromised protective precautions (eg, neutropenic patients) (64\%) and C. difficile infection (59\%).
TABLE 2. Respondent Demographics

\begin{tabular}{lccc}
\hline & $\begin{array}{c}\text { North } \\
\text { America }(\%)\end{array}$ & $\begin{array}{c}\text { International } \\
(\%)\end{array}$ & $\begin{array}{c}\text { Total } \\
(\%)\end{array}$ \\
\hline Respondent role & $\mathbf{N}=\mathbf{2 7 5}$ & $\mathbf{N = 3 2}$ & $\mathbf{N}=\mathbf{3 0 7}$ \\
Infection preventionist & 52 & 34 & 50 \\
Hospital epidemiologist & 38 & 50 & 39 \\
Facility characteristics & & & \\
Type & $\mathbf{N = 2 6 6}$ & $\mathbf{N}=\mathbf{3 0}$ & $\mathbf{N}=\mathbf{2 9 6}$ \\
Hospital & 94 & 100 & 95 \\
Free standing & 4 & 0 & 4 \\
children's hospital & & & \\
Long-term care facility & 1 & 0 & 1 \\
Other & 0 & 0 & 0 \\
Affiliation & $\mathbf{N = 2 7 7}$ & $\mathbf{N}=\mathbf{3 2}$ & $\mathbf{N}=\mathbf{3 0 9}$ \\
University/teaching & 39 & 53 & 40 \\
University/teaching- & 29 & 19 & 28 \\
affiliated & & & \\
Non-teaching & 26 & 22 & 25 \\
VA & 3 & 0 & 3 \\
Specialty & 0 & $\mathbf{N}=\mathbf{1 8}$ & $\mathbf{N}=\mathbf{1 6 8}$ \\
Pediatric facility & $\mathbf{N = 1 5 0}$ & 22 & 23 \\
Yes & 23 & &
\end{tabular}

NOTE. VA, Department of Veterans Affairs.

Fewer respondents reported using as sign for enteric precautions $(18 \%)$. The majority provided both written instructions and pictures on their isolation signs $(90 \%)$, whereas a small proportion provided only written instructions $(8 \%)$ or only pictures (2\%). Of 281 respondents who provided written instructions, 63\% included information only in English. Fewer respondents included information in both English and Spanish $(32 \%)$, and a very small proportion provided information in English, Spanish, and an additional language (5\%). A higher proportion of pediatric facilities than nonpediatric facilities provided signs with information in both English and Spanish ( $50 \%$ vs $29 \%$ ), whereas a higher proportion of nonpediatric facilities than pediatric facilities had information only in English (65\% vs $41 \%)$.

The majority of respondents reported having a policy for visitors entering inpatient isolation rooms (83\%) (Table 4). Of these 286 respondents, $57 \%$ indicated that they had the same requirements for isolation precautions for visitors as for healthcare providers, whereas $42 \%$ indicated that they did not and $1 \%$ indicated that they did not know. Of 211 responses regarding visitors of patients on contact precautions, gowns (96\%) and gloves (94\%) were most frequently required. A very small proportion required surgical masks (6\%), and 1 respondent required N95 respirators. Similarly, when asked about rooms of patients with CRE and/or KPC-producing bacteria, among 227 responses, gowns (97\%) and gloves (97\%) were most frequently required. Surgical masks were required by $9 \%$, and 2 respondents (1\%) required N95 respirators. Visitors entering airborne isolation rooms were most commonly required to wear N95 respirators (68\% of 267 responses), while $38 \%$ of facilities required surgical masks, and 
TABLE 3. Isolation Precautions Signage and Education

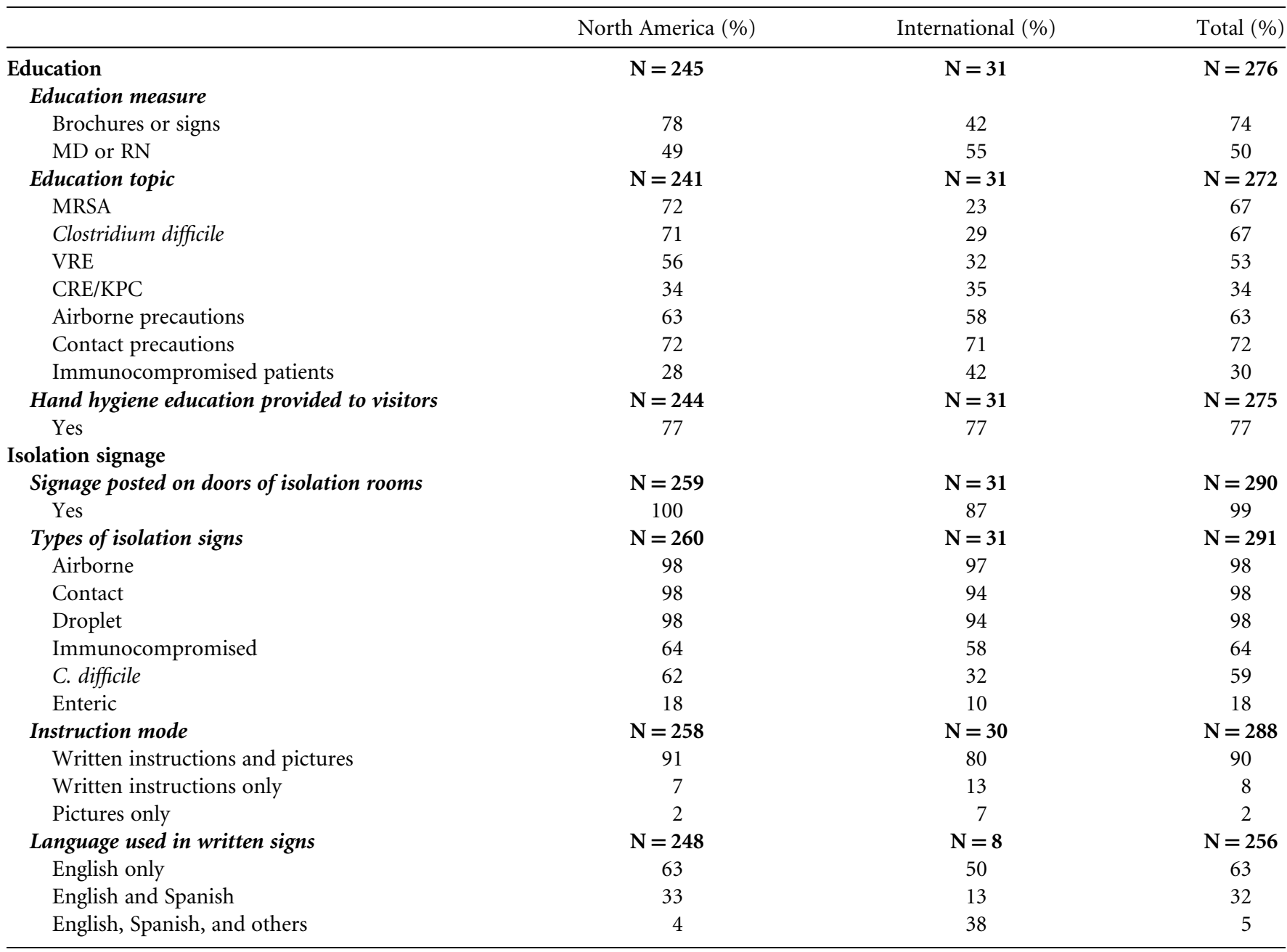

NOTE. MD, medical doctor; RN, registered nurse; MRSA, methicillin-resistant Staphylococcus aureus; KPC, Klebsiella pneumoniae carbapenemase; CRE, carbapenem-resistant enterobacteriaceae; VRE, vancomycin-resistant enterococci.

$10 \%$ required powered air-purifying respirators for respiratory protection. A small proportion also required visitors to wear gowns (13\%) and gloves (11\%). Regarding droplet isolation rooms, surgical masks were most commonly required ( $97 \%$ of 260 responses), but several respondents also required gowns $(25 \%)$ and gloves (26\%).

Most respondents did not monitor visitor compliance with isolation precautions $(77 \%)$ or hand hygiene $(77 \%)$ (Table 5$)$. Several reported enforcing more intensive compliance by visitors of patients with CRE (46\%) and C. difficile (41\%). Among 239 respondents, visitor non-compliance with isolation precautions was most commonly handled by nurse discussion with visitor (93\%), followed by infection preventionist discussion with visitor (55\%), involvement of security team (14\%), and visitor exclusion (7\%); additionally, 40\% mentioned that this response varied depending on unit, shift, etc.

Education on hand hygiene was provided to visitors by $77 \%$ of respondents. Similarly, education about isolation precautions for visitors was provided through brochures or signs by $74 \%$, and/or in person by a physician or registered nurse by $50 \%$. Written patient education brochures or signs for various types of precautions and organisms were available as follows (in descending order of frequency): contact precautions (72\%), MRSA and/or C. difficile (67\%), airborne precautions (63\%), VRE (53\%), CRE and/or KPC (34\%), and immunocompromised protective precautions $(30 \%)$.

Some differences were noted in visitor isolation precaution requirements between healthcare facilities in and outside North America. North American respondents were more likely to report special isolation signs for $C$. difficile (62\%) and enteric precautions (18\%) compared with those outside North America (32\%, and 10\% respectively). Respondents outside North America were more likely to enforce stricter precautions for visitors of patients with CRE/KPC (61\% vs $44 \%$ North American respondents) but less likely to enforce stricter precautions for C. difficile ( $26 \%$ vs $43 \%$ North American respondents). Masks for visitors of patients with CRE/KPC, and gloves and gowns for visitors of patients in airborne 
T A B L 4. Isolation Precaution Policies and Practices

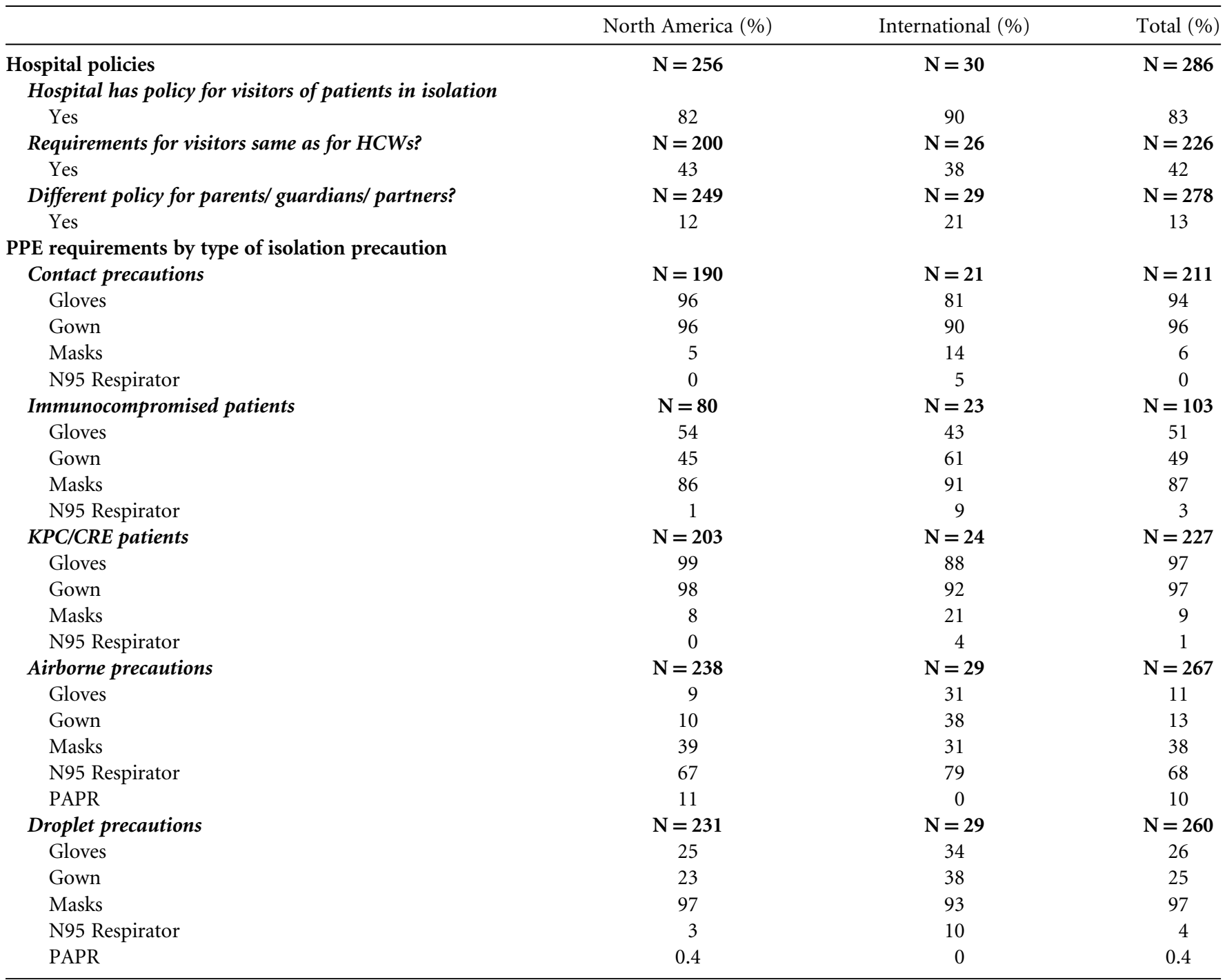

NOTE. HCWs, healthcare workers; KPC, Klebsiella pneumoniae carbapenemase; CRE, carbapenem-resistant Enterobacteriaceae; PAPR, powered air-purifying respirator.

precautions, were more commonly required by respondents outside North America. Respondents outside North America were also more likely to monitor visitor compliance with hand hygiene (39\% vs $19 \%$ ) and with isolation precautions (31\% vs 20\%) compared with North American respondents. A higher proportion of North American respondents provided education about isolation precautions for visitors through brochures and signs ( $78 \%$ vs $42 \%$ outside North America). Similarly, fewer respondents outside North America provided written patient education for specific pathogens (MRSA, VRE, and C. difficile) compared with North American respondents.

\section{I S C U S S I O N}

Hospital visitors may play a significant role in the ecology of healthcare-associated infections. Visitors have initiated or been involved in nosocomial outbreaks ${ }^{23,24,41-43}$ and have an unknown role in transmission of nosocomial bacteria within the hospital environment. Most visitors do not visit $>1$ patient, and therefore do not pose the risk of transmission of pathogens from room to room that can occur via HCWs or shared patient care equipment. Thus, those visitors who do have contact with multiple patients are recommended to use personal protective equipment similar to that used by staff. Epidemic situations mandate visitor restrictions, additional precautions for visitors, or both.

Visitor adherence to infection control precautions seems, in the few heterogeneous studies that report compliance, quite variable. ${ }^{6-9}$ Evidence from several studies suggests that educational interventions encouraging visitor cooperation with infection control precautions do improve adherence. ${ }^{1-13}$ Inspiring consistent hand hygiene by visitors remains a 
TABLE 5. Visitor Compliance with Isolation Precautions

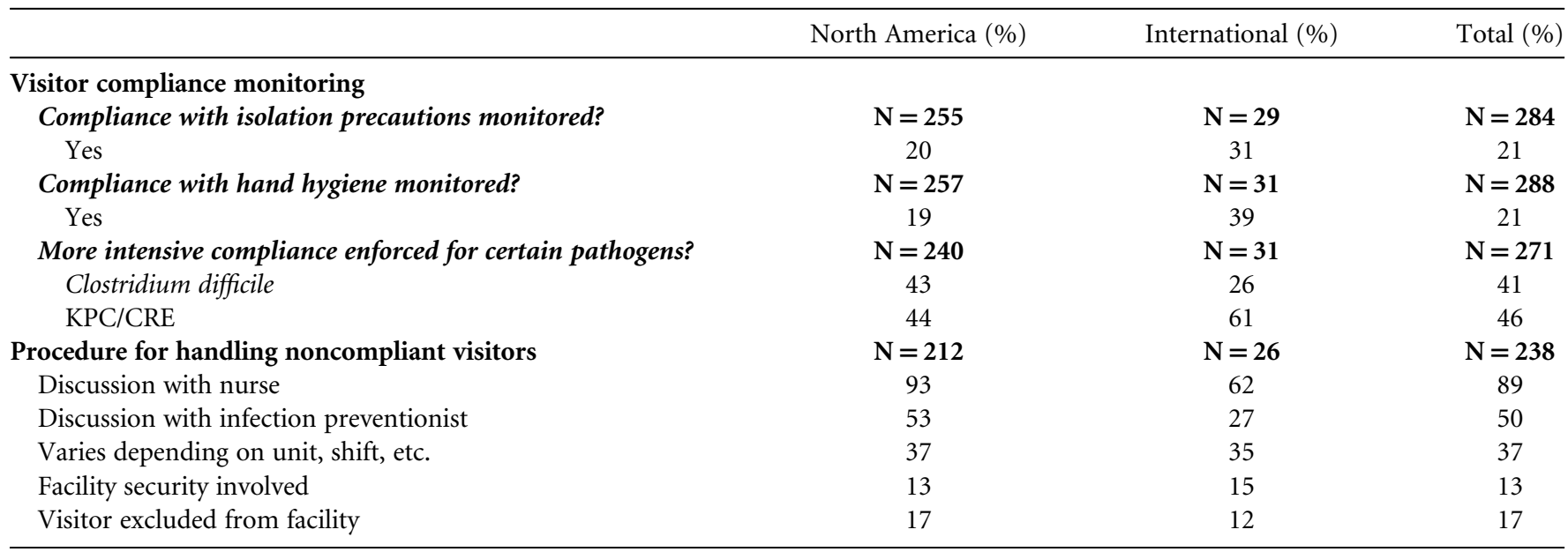

NOTE. KPC, Klebsiella pneumoniae carbapenemase; CRE, carbapenem-resistant Enterobacteriaceae.

significant challenge (as does inspiring hand hygiene by HCWs). In some cases, adherence with gowning and gloving was better among visitors than among HCWs. ${ }^{10}$ Most hospitals in North America have prioritized monitoring of compliance among HCWs rather than among visitors; however, measuring compliance is essential to determining the effect of any intervention and to improving visitor compliance. Nearly all hospitals represented in the survey have isolation signs containing instructions for hand hygiene and the use of personal protective equipment (PPE), and most provide written brochures covering infection control topics. However, in only half of hospitals did visitors receive education on hand hygiene from a physician or nurse; this personal source of guidance may be more influential than written materials. Visitors are a dynamic population within a healthcare facility, so education of visitors must be an ongoing activity.

The screening of visitors for symptoms of infection is another constant challenge, particularly because oversight of potentially symptomatic visitors may not be systematic throughout each facility. Such efforts should be made throughout healthcare facilities, but with particular focus in wards that house immunocompromised adult and pediatric patients. An additional consideration should be the perception, and subsequent impact, of visitors not wearing contact precautions gear on the compliance with isolation precautions among HCWs; certainly, educational interventions is warranted in these settings.

While transient visitors must comply with precautions just for the duration of their visit, family members may serve as a patient's caretaker or advocate and may be at the bedside for many hours, if not around the clock. Our recommendations are intended to be practical and tailored for extended visitors. Family members who have had extended household exposure to the respiratory or airborne illness of their respective patient are generally not required to wear masks or respirators. Those without extensive exposure are recommended to wear masks or, in the case of airborne infections, to avoid entry into the patient room altogether. Fit testing of visitors for N95 respirators is beyond the capability of most infection control departments and would be logistically difficult for most hospitals to incorporate routinely; however, it could potentially be done on a case-by-case basis.

There is a paucity of pediatric data to guide the use of isolation precautions. Given the very limited scientific literature on the subject, studies should be funded to evaluate the role of visitors on the horizontal transmission of pathogens in pediatric facilities, and tools should be developed to reduce the potential negative psychosocial impact of visitor isolation precautions on children and families. Additionally, it is important in pediatrics to distinguish parents/guardian and other household contacts from nonhousehold visitors in terms of risk of previous exposure to the pediatric patient prior to admission.

Until informative pediatric studies are performed, the decision to use isolation precautions for visitors should be balanced by the potential negative psychosocial impact on children as well as the potential interference with bonding, breastfeeding, delivery of family-centered care, and the practicality of enforcing isolation precautions on parents/guardians/visitors. This consideration is especially relevant among visitors who room-in with the patient. Additionally, how frequently PPE should be changed for visitors that are spending prolonged periods of time with patients is unknown. The risk of parents/guardians/visitors as vectors for transmission may be different in pediatric hospitals with all single rooms compared to hospitals with open unit layouts.

For patients colonized or infected with MRSA or potentially other multidrug resistant organisms that were present on admission, employing isolation precautions for parents/guardians/visitors may not be practical. Often these organisms are as prevalent in the community as in the hospital setting, making it unlikely that visitor isolation precautions are 
cost-effective interventions. In many situations the parent/ guardian caring for the patient prior to admission is likely to already be colonized with the multidrug-resistant organism. In situations in which the pediatric patient has potentially acquired a new transmissible infection after admission to the hospital, protection of parent/guardian/visitor by the use of isolation precautions may be considered. However, the risk of infection for parents/guardians/visitors is probably low if they perform good hand hygiene. The additional benefit of wearing gowns and gloves in these scenarios is unclear, and requiring continuous glove use may actually reduce hand hygiene frequency. Family and visitors of patients under either droplet or airborne precautions may consider using isolation precautions. However, isolation precautions must be balanced against the likelihood of the negative psychosocial impact and interference with bonding of mask wearing and the fact that most parents/guardians/household members have already been exposed to the child in the home setting prior to hospitalization and may either be immune to the infectious agent, already in the incubation period, or may represent the adult index case (eg, TB or pertussis) to whom the patient was exposed.

In summary, this guidance paper provides practical recommendations on the use of isolation precautions among visitors to acute care settings. Although most data were obtained from acute care facilities, extrapolation to the postacute care setting is possible. These recommendations should be adapted to hospitals based on their specific situation, annual risk assessment, regional epidemiology, and individual patient needs, particularly among the pediatric population. We strongly recommend further research on this subject to better characterize the role of visitors on the horizontal transmission of pathogens within healthcare facilities.

\section{ACKNOWLEDGMENTS}

Financial support: This study was supported in part by the SHEA Research Network.

Potential conflicts of interest: The spouse of JMG is employed by Teva Pharmaceutical Company.

DM has advisory/consultant roles with Welch Allyn, Sanogiene/Biomed, and 3M as well as the following research grants and/or contracts: University of Maryland School of Medicine, Agency for Healthcare Research and Quality (AHRQ), patient safety and contact precautions; Virginia Health Services Research and Development Service (VA HSRD), comparative effectiveness of isolation precautions; VA HSRD AHRQ; and Centers for Disease Control and Prevention (CDC).

MER has advisory/consultant roles with $3 \mathrm{M}$, CareFusion, and Sharklet as well as the following research grants and/or contracts: $\mathrm{NIH}$, vancomycin treatment algorithm; 3M, efficacy of a peripheral IV dressing; Magnolia, blood culture contamination prevention.

TW has an advisory and/or consultant role with Clorox Healthcare as well as research grants/contracts with the following: $\mathrm{CDC}$, enhancing surveillance among refugees; Clorox Healthcare, the role of improved hydrogen peroxide in the operating room; Pfizer, why patients accept vaccines: a sociobehavioral approach. TW receives organizational benefits from Pfizer, University of Louisville, Research Grant $(>\$ 25,000)$ and Clorox Healthcare, University of Louisville, Research Grant $(>\$ 25,000)$. TW participated in activities with other organizations: annual conference committee, Association for the Healthcare Environment, as well as a research task force.
DW has an advisory/consultant role with and/or has received honoraria from Pfizer, Merck, Germitec, Clorox, and Johnson \& Johnson.

LSMP, DB, SL, TP have nothing to disclose.

Address all correspondence to L. Silvia Munoz-Price, 8701 Watertown Plank Road, PO Box 26509, Milwaukee, WI 53226-0509 (smunozprice@mcw.edu).

\section{REFERENCES}

1. Guyatt GH, Oxman AD, Vist GE, et al. GRADE: an emerging consensus on rating quality of evidence and strength of recommendations. BMJ 2008;336:924-926.

2. Ellingson K, Haas JP, Aiello AE, et al. Strategies to prevent healthcare-associated infections through hand hygiene. Infect Control Hosp Epidemiol 2014;35:937-960.

3. Yokoe DS, Anderson DJ, Berenholtz SM, et al. A compendium of strategies to prevent healthcare-associated infections in acute care hospitals: 2014 updates. Am J Infect Control 2014;42:820-828.

4. Cohen B, Hyman S, Rosenberg L, Larson E. Frequency of patient contact with health care personnel and visitors: implications for infection prevention. Jt Comm J Qual Patient Saf 2012;38: 560-565.

5. Roidad N, Khakoo R. Knowledge and attitudes of visitors to patients in contact isolation. Am J Infect Control 2014;42:198-199.

6. Afif W, Huor P, Brassard P, Loo VG. Compliance with methicillinresistant Staphylococcus aureus precautions in a teaching hospital. Am J Infect Control 2002;30:430-433.

7. Clock SA, Cohen B, Behta M, Ross B, Larson EL. Contact precautions for multidrug-resistant organisms: current recommendations and actual practice. Am J Infect Control 2010;38:105-111.

8. Manian FA, Ponzillo JJ. Compliance with routine use of gowns by healthcare workers (HCWs) and non-HCW visitors on entry into the rooms of patients under contact precautions. Infect Control Hosp Epidemiol 2007;28:337-340.

9. Weber DJ, Sickbert-Bennett EE, Brown VM, et al. Compliance with isolation precautions at a university hospital. Infect Control Hosp Epidemiol 2007;28:358-361.

10. Pettinger A, Nettleman MD. Epidemiology of isolation precautions. Infect Control Hosp Epidemiol 1991;12:303-307.

11. Birnbach DJ, Nevo I, Barnes S, et al. Do hospital visitors wash their hands? Assessing the use of alcohol-based hand sanitizer in a hospital lobby. Am J Infect Control 2012;40:340-343.

12. Nishimura S, Kagehira M, Kono F, Nishimura M, Taenaka N. Handwashing before entering the intensive care unit: what we learned from continuous video-camera surveillance. Am J Infect Control 1999;27:367-369.

13. Fakhry M, Hanna GB, Anderson O, Holmes A, Nathwani D. Effectiveness of an audible reminder on hand hygiene adherence. Am J Infect Control 2012;40:320-323.

14. Randle J, Arthur A, Vaughan N. Twenty-four-hour observational study of hospital hand hygiene compliance. J Hosp Infect 2010;76:252-255.

15. Tan WM, Chlebicka NL, Tan BH. Attitudes of patients, visitors and healthcare workers at a tertiary hospital towards influenza A (H1N1) response measures. Ann Acad Med Singapore 2010;39:303-304.

16. Kellerman SE, Simonds D, Banerjee S, Towsley J, Stover BH, Jarvis W. APIC and CDC survey of Mycobacterium tuberculosis isolation and control practices in hospitals caring for children. Part 1: Patient and family isolation policies and procedures. 
Association for Professionals in Infection and Epidemiology, Inc. Am J Infect Control 1998;26:478-482.

17. Kellerman SE, Saiman L, San Gabriel P, Besser R, Jarvis WR. Observational study of the use of infection control interventions for Mycobacterium tuberculosis in pediatric facilities. Pediatr Infect Dis J 2001;20:566-570.

18. Gupta M, Pursley DM. A survey of infection control practices for influenza in mother and newborn units in US hospitals. Am J Obstet Gynecol 2011;204:S77-S83.

19. Christie CD, Glover AM, Willke MJ, Marx ML, Reising SF, Hutchinson NM. Containment of pertussis in the regional pediatric hospital during the Greater Cincinnati epidemic of 1993. Infect Control Hosp Epidemiol 1995;16:556-563.

20. Beck M, Antle BJ, Berlin D, et al. Wearing masks in a pediatric hospital: developing practical guidelines. Can J Public Health 2004;95:256-257.

21. Muñoz FM, Ong LT, Seavy D, Medina D, Correa A, Starke JR. Tuberculosis among adult visitors of children with suspected tuberculosis and employees at a children's hospital. Infect Control Hosp Epidemiol 2002;23:568-572.

22. Jensen PA, Lambert LA, Iademarco MF, Ridzon R, CDC. Guidelines for preventing the transmission of Mycobacterium tuberculosis in health-care settings, 2005. MMWR Recomm Rep 2005;54:1-141.

23. George RH, Gully PR, Gill ON, Innes JA, Bakhshi SS, Connolly M. An outbreak of tuberculosis in a children's hospital. J Hosp Infect 1986;8:129-142.

24. Weinstein JW, Barrett CR, Baltimore RS, Hierholzer WJ. Nosocomial transmission of tuberculosis from a hospital visitor on a pediatrics ward. Pediatr Infect Dis J 1995;14:232-234.

25. Said MA, Perl TM, Sears CL. Healthcare epidemiology: gastrointestinal flu: norovirus in health care and long-term care facilities. Clin Infect Dis 2008;47:1202-1208.

26. Johnston CP, Qiu H, Ticehurst JR, Dickson C, Rosenbaum P, Lawson $\mathrm{P}$, et al. Outbreak management and implications of a nosocomial norovirus outbreak. Clin Infect Dis 2007;45:534-540.

27. Friesema IH, Vennema H, Heijne JC, et al. Norovirus outbreaks in nursing homes: the evaluation of infection control measures. Epidemiol Infect 2009;137:1722-1733.

28. Aschan J, Ringdén O, Ljungman P, Andersson J, LewensohnFuchs I, Forsgren M. Influenza B in transplant patients. Scand J Infect Dis 1989;21:349-350.

29. Meibalane R, Sedmak GV, Sasidharan P, Garg P, Grausz JP. Outbreak of influenza in a neonatal intensive care unit. J Pediatr 1977;91:974-976.

30. Weingarten S, Friedlander M, Rascon D, Ault M, Morgan M, Meyer RD. Influenza surveillance in an acute-care hospital. Arch Intern Med 1988;148:113-116.
31. Pachucki CT, Pappas SA, Fuller GF, Krause SL, Lentino JR, Schaaff DM. Influenza A among hospital personnel and patients. Implications for recognition, prevention, and control. Arch Intern Med 1989;149:77-80.

32. Sagrera X, Ginovart G, Raspall F, et al. Outbreaks of influenza A virus infection in neonatal intensive care units. Pediatr Infect Dis J 2002;21:196-200.

33. Eibach D, Casalegno JS, Bouscambert M, et al. Routes of transmission during a nosocomial influenza $\mathrm{A}(\mathrm{H} 3 \mathrm{~N} 2)$ outbreak among geriatric patients and healthcare workers. J Hosp Infect 2014;86:188-193.

34. Buchbinder N, Dumesnil C, Pinquier D, et al. Pandemic A/ H1N1/2009 influenza in a paediatric haematology and oncology unit: successful management of a sudden outbreak. J Hosp Infect 2011;79:155-160.

35. Chen LF, Dailey NJ, Rao AK, et al. Cluster of oseltamivir-resistant 2009 pandemic influenza A (H1N1) virus infections on a hospital ward among immunocompromised patients-North Carolina, 2009. J Infect Dis 2011;203:838-846.

36. Carnicer-Pont D, White D, Pike C, Lyons M. Influenza A outbreak in a community hospital in south east Wales, February 2005. Euro Surveill 2005;10:E050217.2.

37. Cunney RJ, Bialachowski A, Thornley D, Smaill FM, Pennie RA. An outbreak of influenza A in a neonatal intensive care unit. Infect Control Hosp Epidemiol 2000;21:449-454.

38. Kashiwagi S, Ikematsu H, Hayashi J, Nomura H, Kajiyama W, Kaji M. An outbreak of influenza A (H3N2) in a hospital for the elderly with emphasis on pulmonary complications. Jpn J Med 1988;27:177-182.

39. Munoz FM, Campbell JR, Atmar RL, et al. Influenza A virus outbreak in a neonatal intensive care unit. Pediatr Infect Dis J 1999;18:811-815.

40. Fanella ST, Pinto MA, Bridger NA, et al. Pandemic (H1N1) 2009 influenza in hospitalized children in Manitoba: nosocomial transmission and lessons learned from the first wave. Infect Control Hosp Epidemiol 2011;32:435-443.

41. (CDC) CfDCaP. Update: severe acute respiratory syndromeworldwide and United States, 2003. MMWR Morb Mortal Wkly Rep 2003;52:664-665.

42. Mukhopadhyay A, Tambyah PA, Singh KS, Lim TK, Lee KH. SARS in a hospital visitor and her intensivist. J Hosp Infect 2004;56:249-250.

43. Gopalakrishna G, Choo P, Leo YS, et al. SARS transmission and hospital containment. Emerg Infect Dis 2004;10:395-400.

44. Dwosh HA, Hong HH, Austgarden D, Herman S, Schabas R. Identification and containment of an outbreak of SARS in a community hospital. CMAJ 2003;168:1415-1420. 